\title{
Free-operant extinction as a function of magnitude of reward and number of reinforcements'
}

\author{
KENNETH TRAUPMANN AND JOHN J. PORTER, \\ DEPARTMENT OF PSYCHOLOGY, UNIVERSITY OF \\ WISCONSIN-MILWAUKEE, Milwaukee, Wisc., 53201
}

Resistance to extinction was measured in a free-operant bar-pressing situation with $.02 \mathrm{ml}$ or $.20 \mathrm{ml}$ water reward, for 10 , 60 , or 120 reinforcements. In two experiments, CRF and FR:8, respectively, there was evidence for an inverse relation between resistance to extinction and number of reinforcements at $.20 \mathrm{ml}$; at the small reward there was a positive relation between resistance to extinction and number of reinforcements.

Previous investigators have demonstrated an inverse relationship between resistance to extinction and number of reinforcements in the discrete-trial runway (North \& Stimmel, 1960; Ison, 1962). The results of Ison \& Cook (1964) indicated that the inverse relationship was due to the large magnitude of reward used in these studies.

Investigations of resistance to extinction in the free-operant bar-pressing situation (Williams, 1938; Perin, 1942; Harris \& Nygaard, 1961; Dyal \& Holland, 1963) have consistently demonstrated a positive relationship between resistance to extinction and number of reinforcements. However, these studies have utilized relatively small reinforcements.

The present two experiments were an attempt to demonstrate, in a free-operant situation, an inverse relationship between resistance to extinction and number of acquisition reinforcements with a large reward, while replicating previous free-operant results with a small reward.

\section{EXPERIMENT 1}

Method. Sixty 150-day-old female rats were assigned to six groups of 10 Ss each. The groups received either $.02 \mathrm{ml}$ or $.20 \mathrm{ml}$ of water reward for

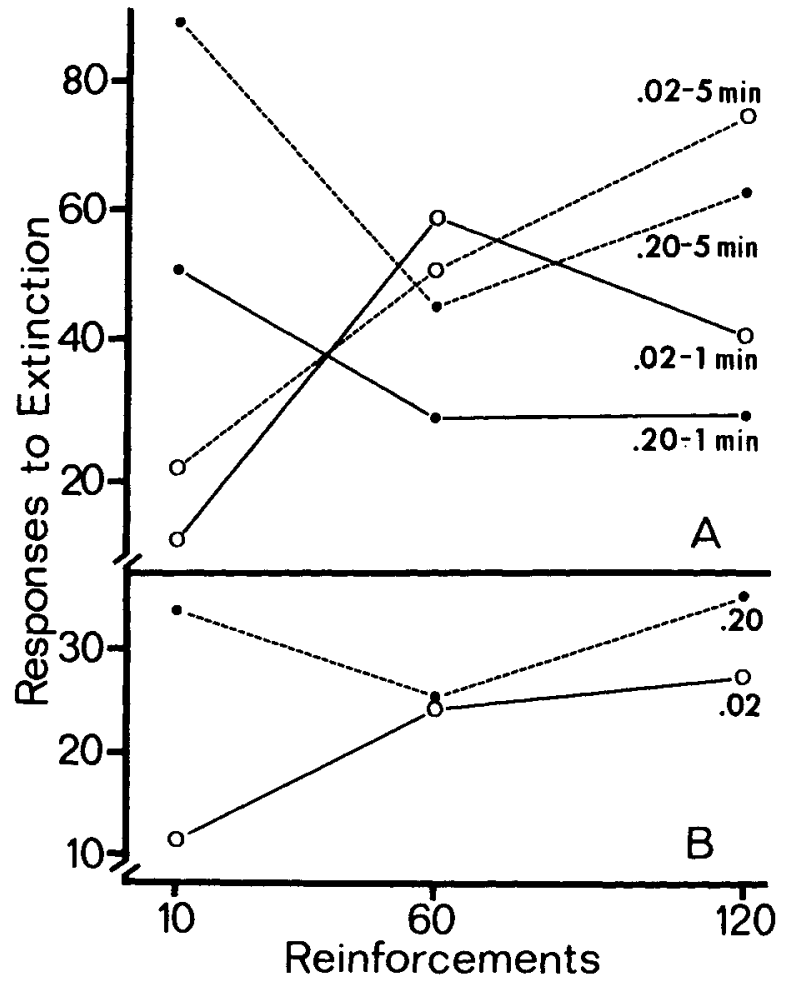

Fig. 1. Mean number of responses to extinction. Part $A$ of the figure is for Experiment 1. Part B of the figure is for Experiment 2. For part $A$ the dotted lines refer to the adjusted data to the 5 min extinction criterion while the solid lines refer to the 1 min criterion.

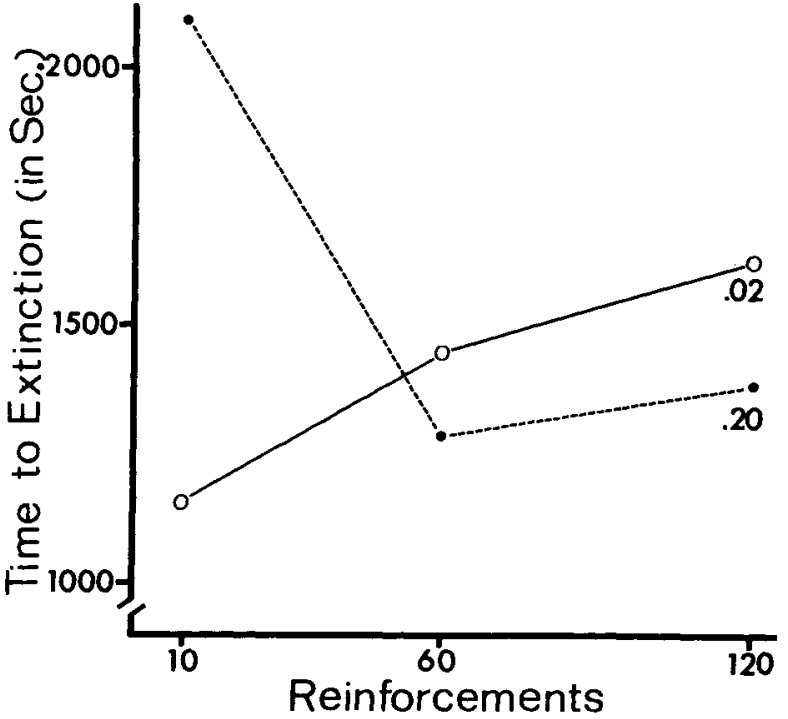

Fig. 2. Time in sec to reach the 5-min extinction criterion. The points on the figure represent the mean time in sec to criterion for each group.

either 10,60 , or 120 reinforcements. The Ss were run in standard Lehigh-Valley operant chambers with liquid dippers which dipped into a trough of water upon each bar-press and returned.

On Day 1, Ss were deprived of water for $24 \mathrm{~h}$ and then from Day 2 on were given water for $5 \mathrm{~min}$ daily. On Days 4 and 5 the $S s$ were dipper trained, on a $30 \mathrm{sec}$ VI schedule, for 30 and 15 reinforcements respectively. On Day 6 , Ss were placed in the chamber and given either 10,60 , or 120 reinforced bar-presses on a CRF schedule. On Day 7, Ss were extinguished to a criterion of $5 \mathrm{~min}$ without a response. Both total time and number of responses to 1 and 5 min extinction criteria were measured.

Results. There were no significant differences in the total number of responses to the $5 \mathrm{~min}$ extinction criterion. However, an analysis of variance over the $1 \mathrm{~min}$ criterion data (Fig. 1A) showed a significant interaction between magnitude of reward and number of reinforcements, $F=4.52$, df $=2 / 54, p<.025$. The interaction resulted from the superiority of the $.20-10$ group over the $.02-10$ group, $\mathrm{F}=10.08, \mathrm{df}=1 / 54, \mathrm{p}<.005$, while there was no significant difference between the .02 and .20 groups after 60 or 120 reinforcements. Furthermore, Newman-Keuls tests showed that the $.02-10$ group made significantly fewer responses than the $.02-60$ group $(p<.05)$. None of the .20 groups differed significantly from each other.

Post hoc examination of the 5-min extinction criterion data showed that in many instances one $S$ was extremely divergent from the remainder of the group, so these data were reanalyzed omitting the most divergent score from each of the groups. An analysis of variance over these data (Fig. 1A) showed a significant interaction between magnitude of reward and number of reinforcements, $F=9.59, \mathrm{df}=2 / 48, \mathrm{p}<.001$. Newman-Keuls tests indicated that this interaction resulted from more responses to extinction by the .20-10 group as compared to the .20-60 and $.20-120$ groups $(p<.05$ ), which did not differ significantly, while the .02-10 group made significantly fewer responses to extinction than the $.02-60(p<.05)$. Neither of the latter groups differed from the $.02-120$ group.

Although the data for total time to extinction had the same appearance as that for total responses, no significant differences were found using either a 1 -min or $5 \mathrm{~min}$ criterion.

\section{EXPERIMENT 2}

To counteract the high variability observed in Experiment 1 , Ss in Experiment 2 were run on FR:8 and were male albino rats rather than females. 
Method. Seventy-two rats were assigned to six groups according to the same factorial design used in Experiment 1. The only procedural change was that Ss were given one day of shaping to FR: 8 following the second day of dipper training. The Ss in Experiment 2 were given only 30 reinforcements per day, although extinction took place in one day.

Results. A factorial analysis of variance on the data for total responses to the $5 \mathrm{~min}$ criterion (Fig. 1B) showed a significant superiority of the .20 groups over the .02 groups, $F=3.61$, df $=$ $2 / 66, \mathrm{p}<.05$; and a significant interaction between the two variables $F=5.21, \mathrm{df}=2 / 66, \mathrm{p}<.01$. The .02 groups showed a significant increase in responses to extinction as a function of the number of reinforcements, $F=6.07$, df $=2 / 66, p<.005$. Newman-Keuls tests indicated that the .02-10 group gave significantly fewer responses to extinction than either the $.02-60$ or $.02-120$ groups, which did not differ significantly $(p>.05)$.

A factorial analysis of variance on the total time to the 5-min criterion (Fig. 2) showed a significant interaction between magnitude of reward and number of rewards, $\mathrm{F}=5.87, \mathrm{df}=2 / 66$, $\mathrm{p}<.005$. For the .20 groups, there was a significant decrease in time to extinction as a function of the number of reinforcements, $F=5.27, \mathrm{df}=2 / 66, \mathrm{p}<.01$. Newman-Keuls tests showed that the $.20-10$ group took significantly longer to extinguish than the $.20-60$ and $.20-120$ groups $(\mathrm{p}<.01)$, which did not differ significantly from each other $(p>.10)$. The .02 groups showed a nonsignificant trend $(p>.05)$ to increase in time to extinction as a function of number of reinforcements.

Discussion

The present two studies yielded some evidence of an inverse relationship between number of reinforcements and free-operant extinction, when a large reinforcement was employed. Both the amended responses to the 5-min criterion for the CRF Ss, and the total time to the same criterion data for the 8:1 Ss, strongly suggested this inverse relationship. The 1-min criterion data from the CRF Ss showed the proper trend, but did not reach an acceptable level of statistical significance. Only the number of responses to extinction data for the 8:1 Ss failed to show the expected trend at the large reinforcement magnitude. For the $.02 \mathrm{ml}$ groups, resistance to extinction increased as a function of number of reinforcements with the exception of the 1-min criterion data for the CRF Ss.

While the present studies did demonstrate an inverse relationship between resistance to extinction and number of reinforcements in free-operant responding, the demonstration was relatively weak. The discrete-trial barpressing results of Tombaugh (1967) suggest that more reinforcements may be necessary in order to clearly demonstrate an inverse relationship between number of reinforcements and resistance to extinction with a large reward.

\section{REFERENCES}

DYAL, J. S., \& HOLLAND, T. A. Resistance to extinction as a function of the number of reinforcements. Amer. J. Psychol, 1963, 76, 332-333.

HARRIS, P., \& NYGAARD, J. E. Resistance to extinction and the number of reinforcements. Psychol. Rep., 1961, 8, 233-234.

ISON, J. Experimental extinction as a function of number of reinforcements. J. exp. Psychol., 1962, 64, 314-317.

ISON, J., \& COOK, P. Extinction performance as a function of incentive magnitude and number of acquisition trials. Psychon. Sci., 1964, 1, 245-246.

NORTH, A., \& STIMMEL, D. Extinction of an instrumental response following a large number of reinforcements. Psychol. Rep., 1960, 6, 227-234.

PERIN, C. T. Behavior potentiality as a joint function of the amount of training and the degree of hunger at the time of extinction. $J$, exp. Psychol., 1942, 30, 93-113.

TOMBAUGH, T. M. The overtraining extinction effect with a discrete-trial bar press procedure. J. exp. Psychol., 1967, 73, 632-634.

WILLIAMS, S. Resistance to extinction as a function of the number of reinforcements. J. exp. Psychol., 1938, 23, 506-522.

NOTE

1. This research was supported by NSF Grant GB-3466 to the second author. punishment. Psychon. Sci, 1968, 10(7), 245-246.-The reference to Hurwitz et al should be Hurwitz, H. M., Bolas, D., \& Haritos, M. Vicious circle behavior under two shock intensities. Brit. J. Psychol., 1961 , 52, 377 (not the J. app. Psychol. Res.). 